\title{
Notice of redundant publication
}

BMJ Case Reports wishes to inform its readers of the following redundant publication.

The publication:

Vyawahare S, Banda NR, Barodiya A, et al. A rare occurrence of peripheral ossifying fibroma in the first decade of life and its management. BMJ Case Rep. Published Online:15 Mar 2013. doi: 10.1136/bcr-2013-009084.

Considerably overlaps with the article:

Nazareth B, Arya H, Arora SAR, et al. Peripheral Ossifying fibroma: a clinical report. Int J Odontostomat 2011;5:153-6.

The article in BMJ Case Reports has been retracted.

BMJ Case Rep 2013. doi:10.1136/bcr-2013-009084rp 